\title{
Are the Parents' and Their Children's Physical Activity and Mode of Commuting Associated? Analysis by Gender and Age Group
}

\author{
Fernando Rodríguez-Rodríguez ${ }^{1, *(1)}$, Francisco Javier Huertas-Delgado ${ }^{2}($, \\ Yaira Barranco-Ruiz ${ }^{3}$ (D) , María Jesús Aranda-Balboa ${ }^{3}$ and Palma Chillón ${ }^{3}$ (D) \\ 1 IRyS Group, School of Physical Education, Pontificia Universidad Católica de Valparaíso, \\ 2374631 Valparaíso, Chile \\ 2 Teacher Training Centre La Inmaculada, University of Granada, 18003 Granada, Spain; fjhuertas@ugr.es \\ 3 PROFITH “PROmoting FITness and Health through Physical Activity" Research Group, \\ Department of Physical Education and Sport, Faculty of Sport Sciences, University of Granada, \\ 18001 Granada, Spain; ybarranco@ugr.es (Y.B.-R.); mjab@ugr.es (M.J.A.-B.); pchillon@ugr.es (P.C.) \\ * Correspondence: fernando.rodriguez@pucv.cl; Tel.: +56-9-8444-2828
}

Received: 21 August 2020; Accepted: 18 September 2020; Published: 20 September 2020

check for updates

\begin{abstract}
Background: Some studies have reported a positive parent-child association between physical activity (PA), but few have examined the difference in these associations concerning both genders. The objective of this study was to establish the association between moderate to vigorous physical activity (MVPA) and mode of commuting (MC) of the parents with their children by gender and age group. Methods: This cross-sectional study included 686 mothers and fathers $(43.4 \pm 6.5$ years old) and their children (children $9.7 \pm 1.7 \mathrm{y}$. and adolescents $14.0 \pm 1.7 \mathrm{y}$.) Each participant completed a questionnaire on PA and MC. Chi-square test, odds ratio for categorical variables, and lineal regressions for continuous variables were used to examine the parent-child associations. Results: An inverse association was found between fathers-children in the weekend MVPA in children and between mothers-adolescents in out-of-school and weekend MVPA. An inverse association was found in MVPA between mothers-girls, and the different parents' MC to work was positively associated with the MC to school in children and adolescents except for the association AC parents-adolescents. The AC was mainly associated between mothers and girls and boys. Conclusions: A weak association in parent-child MVPA but a strong association in MC between parent-child was found.
\end{abstract}

Keywords: active transport; active commuting to school; school; schoolchildren; family

\section{Introduction}

Regular physical activity (PA) has been associated with numerous health benefits at all stages of life, especially in youth [1,2]. To obtain these benefits, it is recommended to perform at least $60 \mathrm{~min} /$ day of moderate to vigorous PA (MVPA) in young people and at least $150 \mathrm{~min} /$ week of MVPA in adults [3,4]. Unfortunately, a small proportion of children/adolescents [5,6] and adults [7] meet these recommendations. On the other hand, the studies have shown overall that boys and children are more active than girls and adolescents, respectively [8].

Children's PA habits are shaped by their parents, particularly in younger children compared with adolescents [9]. It has been estimated that children with active parents are three to four times more active than children with inactive parents [10]. In addition, a greater PA relationship with children compared to adolescents has been demonstrated [11]. 
Moreover, the effect of the parent gender on children's PA has been previously examined. For instance, a positive association has been found between mothers' sport participation and children's leisure time PA, but it remained significant only in girls [12]. Another Brazilian study observed a greater positive association between the mother's PA with adolescent boys and girls, but there was no association for fathers [13]. Furthermore, the PA of both parents presented a greater association with girls than with boys. In contrast, a study demonstrated that only the mother's MVPA was associated with their children's MVPA [14]. Another study showed a significant positive association between fathers and boys only [15]. Despite that fact, studies have focused on the mother-child relationship, and relatively little attention has been paid to the role of fathers in their children's PA [16,17]. Mothers play a greater role in planning and organizing children's PA, while fathers are more likely to model children's PA [18]. Until now, the evidence on PA gender-specific parental influence (e.g., mother-daughter, mother-son, father-daughter, father-son) is still inconsistent.

It has been established that active commuting to school (ACS) or active commuting (AC) to work (walking or cycling) is an opportunity to increase PA levels $[19,20]$. Moreover, ACS is related to nine sustainable development goals, emphasizing the third (health and well-being) and the eleventh (sustainable cities and communities) [21]. However, around $50 \%$ of youths and $75 \%$ of adults passively commute to school [22] and to work [23], respectively. Multiple factors influence whether schoolchildren actively travel to/from school [24]. The educational level and the body weight [21], the socioeconomic level [25], and the unemployment of the parents [26] are factors that affect children's ACS and have been studied. However, few studies have linked the parent's AC with their children's ACS, and even fewer take into account gender. A Spanish study observed a positive association between parents' AC and children's ACS [26]. Indeed, the number of steps/day of the parents has been positively associated with the number of steps/day of the children [27], mainly associated between mothers and daughters [28]. Specifically, it has been reported that, for every 1000 steps/day that parents increase, their children increase by 260 steps/day [29]. Therefore, further quality studies analyzing the influence that the fathers' or the mothers' AC has on boys' or girls' ACS as well as taking into account the age (e.g., children or adolescents) are needed. In the current study, it is expected to verify the association between parent-child PA and to find new associations between the AC that support the importance of the family in the development of active behaviors. This would allow targeting interventions to more specific sectors and groups in order to achieve successful results.

According to the previous information, the main objective of this study was to establish the association between moderate to vigorous physical activity (MVPA) and mode of commuting (MC) of the parents with their children by gender and age group.

\section{Materials and Methods}

\subsection{Study Design and Participants}

It is a cross-sectional study with children and parent's participation carried out in Granada (Spain) and Valparaíso (Chile). Data were obtained as part of the "Cycling and Walk to School" (PACO, for its Spanish acronym) study, focused on promoting PA and, particularly, active commuting to and from school. A total of 2526 children and adolescents and 1959 of their parents participated. Twenty schools were invited to participate in the study as a non-randomized sample. From the total children sample, 1807 participants could not be paired with parents' data, and 34 did not report their gender and were excluded ( $72.8 \%$ of the total sample). A total of 572 parents could not be paired with children's data, and 703 without gender data were excluded ( $65 \%$ of the total sample). Finally, a total of 686 paired parents ( $52.8 \%$ mothers) and their respective children ( $33.7 \%$ girls) were considered. They belonged to fifteen schools of Granada Spain $(n=494)$ and five schools of Valparaíso in Chile $(n=192)$. The age (mean \pm standard deviation) of each group was: parents $43.4 \pm 6.5$ years old), children $9.7 \pm 1.7$ years old, and adolescents $14.0 \pm 1.7$ years old. 


\subsection{Sociodemographic Factors}

Children and adolescents completed a questionnaire on sociodemographic characteristics, which includes school name, age, birth date, school grade and class, gender, birth country, mother's and father's birth country, and full postal address. Parents completed a questionnaire on sociodemographic variables such as age, gender, monthly income (none; <499€; 500-999€; 1000-1499€; 1500-1999€; 2000-2499€; 2500-2999€; 3000-4999€; >5000€) and highest educational level (no study, primary school, secondary school, bachelor, professional, university degree). The monthly income was dichotomized in $\leq 999 €$ or $\geq 1000 €$, and the highest educational level was dichotomized in secondary/bachelor's (no study, primary school, secondary school, bachelor) or professional/university (professional or university degree).

\subsection{Physical Activity}

The questionnaire to determine the weekly school and extracurricular PA in children and adolescents was the Youth Activity Profile (YAP), that was self-reported by children and adolescents. The YAP provides a simple and low-cost method that has already been calibrated and validated to accurately estimate children's MVPA and sedentary behaviors at the group level [30]. The self-reported YAP questionnaire comprises three items about participation in different types of activities and sports in the last seven days. The items were "PA in school" (physical education, recess, and ACS), "out-of-school PA" (before and after school and PA at the weekend), and "sedentary time" (not considered in current study). Each item was scored on a scale from 1 (low PA) to 5 (high PA), and the average score denoted the YAP score (1-5). The questions were categorized into three areas: PA at school, out-of-school PA, and weekend PA. Then, PA in children and adolescents was established by transforming the YAP score to minutes/day in MVPA using the Fairclough equations [31]. We obtained the min/day in MVPA at school, out-of-school MVPA, and weekend MVPA separately for children and adolescents and for boys and girls. The cut-off point to be "physically active" was $>60 \mathrm{~min} /$ day MVPA [32], classified as meeting MVPA recommendations. Those children who did not comply were considered as "physically inactive".

The International Physical Activity Questionnaire (IPAQ, short version) was used to assess the parents' MVPA. This questionnaire has been validated in 12 countries [33,34], showing acceptable psychometric properties to measure the MVPA levels in one week. The IPAQ allows determining the PA in min/week. Additionally, this instrument determines intensity categories as sedentary time, light PA, moderate PA, and vigorous PA. According to the MVPA international recommendations, parents were classified as physically active when they completed $\geq 150 \mathrm{~min} /$ week (meeting the recommendations) and physically inactive when they did not reach $150 \mathrm{~min} /$ week (not meeting the recommendations).

\subsection{Mode of Commuting}

The instruments used to assess the mode of commuting were a student (for children and adolescents) and a family (for parents) questionnaire from the PACO Study that have been developed at the University of Granada, Spain by a group of experts in this topic [35]. The questions about the MC to school derive from an exhaustive review of previous studies of the scientific literature on AC [36] and have been reliable [37] and validated in Spanish population [38] and validated in Chilean population [39]. In children and adolescents, the questions included in the questionnaire were: (1) "How do you usually get to school?" and (2) "How do you usually get home from school?". The possible answers were: walking, cycling, car, motorcycle, school bus, public bus, metro/train, and other (the mode description was required). The final variable to analyze was usual active mode of commuting to school.

The questions about parent's MC to work have gone through an exhaustive reliability process [40]. In parents, the questions were: (1) “How do you usually get to work?" and (2) "How do you usually 
get home from work?". The possible answers were: walking, cycling, car, motorcycle, public bus, metro/train, or other (the mode description was required).

MC for children and parents was categorized as "active" (walking and cycling) and "passive" (car, motorcycle, bus, metro/train). Additionally, the "passive" commuting was divided into private mode of commuting (car, motorcycle) and public mode of commuting (public bus, metro, train). In addition, the final variable of usual active commuting included one or two trips to school (to, from, or both).

\subsection{Procedures}

The questionnaires (paper-and-pencil) were administered at participating schools between 2015 and 2018. The children and the adolescents' questionnaires were implemented by the researcher staff during the school hours within the physical education lessons and approximately by $30 \mathrm{~min}$. Both research team and schoolteachers presented this questionnaire for clarification purposes. The family's questionnaire was completed once by parents, and it was delivered to children and completed at home by parents.

Parents signed an informed consent that described the objectives and the characteristics of this study and allowed their children to participate, in accordance with the Declaration of Helsinki. This study was reviewed and accepted by both the Ethical Committee of the University of Granada Spain (No.162/CEIH/2016) and the Ethical Committee of the Pontificia Universidad Católica de Valparaíso, Chile (CCF02052017).

\subsection{Statistical Analysis}

Descriptive statistics were calculated for study variables, mean $(\mathrm{M})$ and standard deviation $( \pm \mathrm{SD})$ for continuous variables and frequency (\%) for categorical variables. The comparison of categorical variables according to gender in each group (parents (mothers and fathers), children (girls and boys), adolescents (girls and boys)) was examined using the Chi-Square test.

To establish the association between parent-child's MVPA, several lineal regressions through a standardized coefficient (B) were used for the whole sample for boys and for girls separately. The min/day of MVPA in children and the dichotomic variable of meeting the recommendations for parents were included. Children's MVPA was established as the dependent variable. For the MC association, several binary logistic regressions were performed. Children's MC to school was established as the dependent variable. The references for MC were (a) "passive" for active commuting; (b) "passive + private" for public commuting; (c) "passive + public" for private commuting. The associations were adjusted for parents' educational level and age of the children. IBM SPSS ${ }^{\circledR}{ }^{\circledR} \mathrm{v} 21$ (New York, NY, USA) was used for all the analyses. A $p<0.05$ value was established as statistically significant.

\section{Results}

Parent-child sociodemographic characteristics are presented in Table 1. The children and the parents' MVPA and MC separated by gender are presented in Table 2. The percentage of physically inactive girls was significantly higher than boys for both children $(p<0.001)$ and adolescents $(p=0.003)$. Parents of children and parents of adolescents were also mainly physically inactive $(75 \%$ and $84.9 \%$, respectively) in both genders (mother and father).

The associations between the parents' MVPA and their offspring's MVPA by gender are presented in Table 3. In the children group, only the fathers' MVPA was positively associated with girls' MVPA ( $(=0.24 ; 95 \%$ CI: $0.00-1.80)$ and negatively associated with boys' MVPA ( $\beta=-0.27 ; 95 \%$ CI: $-2.10-0.19)$, both of them at the weekend. In adolescents the mothers' MVPA was negatively associated with the MVPA in all out-of-school $(B=-0.23 ; 95 \% \mathrm{CI}:-5.12-0.27)$ and in girls during the weekend ( $(=-0.38 ; 95 \% \mathrm{CI}:-2.35-0.40)$.

The associations between the parents' $\mathrm{MC}$ to work and their children $\mathrm{MC}$ by gender are presented in Table 4. Mothers' AC was associated with girls' and boys' ACS in children (OR $=4.48$; $95 \%$ CI: 
2.01-9.96 and OR $=5.19 ; 95 \%$ CI: 1.92-14.05, respectively). Fathers' AC to work was only associated with the girls' ACS (OR = 3.69; 95\% CI: 1.83-7.47). Girls presented higher odds to use public commuting if fathers used public commuting. Public commuting was only associated between fathers and girls $(\mathrm{OR}=12.62 ; 95 \% \mathrm{CI}: 2.08-76.55)$. Mothers of children who used private commuting increased the likelihood that girls and boys also used private commuting $(\mathrm{OR}=2.24 ; 95 \% \mathrm{CI}$ : $1.32-3.80$ and OR =6.26; 95\% CI: 2.84-13.81, respectively). Children had higher odds to use private commuting when fathers used private commuting (girls $\mathrm{OR}=3.08$; 95\% CI: $1.83-5.16$ and boys OR $=7.96$; 95\% CI: 3.48-18.20). In adolescents, no associations were found between parents' AC to work and children ACS. In fathers, an association with girls was observed in public modes (OR $=6.30 ; 95 \% \mathrm{CI}$ : 2.21-17.94) as well as with mothers $(\mathrm{OR}=4.59 ; 95 \% \mathrm{CI}$ : 1.76-11.94). Additionally, when mothers used private commuting, boys presented higher odds to use private commuting ( $\mathrm{OR}=17.21$; 95\% CI: 2.60-113.70), and when fathers used private commuting, girls showed higher odds to use private modes of commuting $(\mathrm{OR}=12.72 ; 95 \% \mathrm{CI}: 5.01-32.31)$.

Table 1. Sociodemographic characteristics of the parents of children and parents of adolescents.

\begin{tabular}{|c|c|c|c|c|c|c|c|}
\hline & \multicolumn{2}{|c|}{ Overall } & \multicolumn{2}{|c|}{ Parents of Children } & \multicolumn{2}{|c|}{$\begin{array}{c}\text { Parents of } \\
\text { Adolescents }\end{array}$} & \multirow[t]{2}{*}{$p$-Value } \\
\hline & $\mathbf{N}$ & $(\%)$ & $\mathbf{N}$ & $(\%)$ & $\mathbf{N}$ & $(\%)$ & \\
\hline \multicolumn{8}{|l|}{ Children gender $(n=686)$} \\
\hline Girls & 232 & $(33.8)$ & 153 & (34.9) & 79 & $(32.0)$ & \multirow[b]{2}{*}{0.249} \\
\hline Boys & 454 & $(66.2)$ & 286 & $(65.1)$ & 168 & $(68.0)$ & \\
\hline Children age $(M \pm S D)$ & \multicolumn{2}{|c|}{$11.3 \pm 2.7$} & \multirow{2}{*}{\multicolumn{2}{|c|}{$9.7 \pm 1.7$}} & \multicolumn{2}{|c|}{$14.0 \pm 1.7$} & $* *<0.001$ \\
\hline \multicolumn{7}{|l|}{ Parent gender $(n=686)$} & \\
\hline Mothers & 362 & $(52.8)$ & 245 & $(55.8)$ & 118 & $(47.7)$ & \multirow{2}{*}{$* 0.026$} \\
\hline Fathers & 323 & $(47.2)$ & 194 & $(44.2)$ & 129 & $(52.3)$ & \\
\hline $\begin{array}{c}\text { Parent age (Mean } \pm \text { SD) } \\
\text { Mother's highest } \\
\text { educational level }(n=614)\end{array}$ & & 6.5 & & 5.7 & & & $* *<0.001$ \\
\hline Secondary school/bachelor's & 330 & $(53.7)$ & 194 & $(49.7)$ & 136 & $(60.7)$ & \multirow{2}{*}{$* 0.009$} \\
\hline Professional/university & 284 & $(46.3)$ & 196 & $(50.3)$ & 88 & (39.3) & \\
\hline \multicolumn{8}{|l|}{$\begin{array}{l}\text { Father's highest educational } \\
\text { level }(n=675)\end{array}$} \\
\hline Secondary school/bachelor's & 314 & $(46.5)$ & 190 & $(43.9)$ & 124 & $(51.2)$ & \multirow{2}{*}{0.066} \\
\hline Professional/university & 361 & $(53.5)$ & 243 & $(56.1)$ & 118 & $(48.8)$ & \\
\hline \multicolumn{8}{|l|}{$\begin{array}{l}\text { Mother's monthly income } \\
\qquad(n=336)\end{array}$} \\
\hline$<1000 €$ & 127 & $(37.8$ & 75 & $(33.0)$ & 52 & $(47.7)$ & \multirow{2}{*}{$* 0.009$} \\
\hline$>1000 €$ & 209 & $(62.2)$ & 152 & $(67.0)$ & 57 & (52.3) & \\
\hline \multicolumn{8}{|l|}{$\begin{array}{l}\text { Father's monthly income } \\
\qquad(n=463)\end{array}$} \\
\hline$<1000 €$ & 278 & $(60.0)$ & 183 & $(57.0)$ & 95 & $(66.9)$ & \multirow{2}{*}{$* 0.045$} \\
\hline$>1000 €$ & 185 & $(40.0)$ & 138 & $(43.0)$ & 47 & $(33.1)$ & \\
\hline
\end{tabular}


Table 2. Descriptive data of parents' and their children physical activity and mode of commuting by gender.

\begin{tabular}{|c|c|c|c|c|c|c|c|}
\hline & \multicolumn{7}{|c|}{ Children } \\
\hline & \multirow[b]{2}{*}{ Overall } & \multicolumn{2}{|c|}{ Children } & \multicolumn{4}{|c|}{ Adolescents } \\
\hline & & Girls & Boys & \multirow{2}{*}{$p$-Value } & Girls & Boys & \multirow{2}{*}{$p$-Value } \\
\hline & N (\%) & N (\%) & N (\%) & & N (\%) & N (\%) & \\
\hline \multicolumn{8}{|l|}{ MVPA $^{a}$} \\
\hline Physically active & $185(33.3)$ & $62(25.0)$ & $111(88.8)$ & \multirow{3}{*}{$<0.001^{* *}$} & $4(3.1)$ & $8(15.1)$ & \multirow{3}{*}{$0.003 *$} \\
\hline Physically inactive & $370(66.6)$ & $186(75.0)$ & $14(11.2)$ & & $125(96.9)$ & $45(84.9)$ & \\
\hline MC to school & & & & & & & \\
\hline Active & $220(32.1)$ & $89(31.1)$ & $50(32.7)$ & \multirow{2}{*}{0.738} & $52(31.0)$ & $29(37.2)$ & \multirow{2}{*}{0.333} \\
\hline \multirow[t]{5}{*}{ Passive } & $465(67.9)$ & $197(68.9)$ & $103(67.3)$ & & $116(69.0)$ & $49(62.8)$ & \\
\hline & \multicolumn{7}{|c|}{ Parents } \\
\hline & & \multicolumn{2}{|c|}{ Parents of Children } & \multicolumn{4}{|c|}{ Parents of Adolescents } \\
\hline & Overall & Mother & Father & \multirow{2}{*}{$p$-Value } & Mother & Father & \multirow{2}{*}{$p$-Value } \\
\hline & N (\%) & N (\%) & N (\%) & & N (\%) & N (\%) & \\
\hline \multicolumn{8}{|l|}{ MVPA $^{a}$} \\
\hline Physically active & $49(7.2)$ & $7(2.9)$ & $28(14.4)$ & \multirow{3}{*}{$<0.001 * *$} & $3(2.6)$ & $11(8.5)$ & \multirow{3}{*}{0.044 * } \\
\hline Physically inactive & $635(92.8)$ & $217(97.1)$ & $166(85.6)$ & & $114(97.4)$ & $118(91.5)$ & \\
\hline MC to work & & & & & & & \\
\hline Active & $216(31.6)$ & $81(33.2)$ & $51(26.4)$ & \multirow{2}{*}{0.126} & $44(37.6)$ & $40(31.0)$ & \multirow{2}{*}{0.276} \\
\hline Passive & $467(68.4)$ & $163(66.8)$ & $142(73.6)$ & & $73(62.4)$ & $89(69.0)$ & \\
\hline
\end{tabular}

MVPA; moderate to vigorous physical activity; MC: mode of commuting. Statistical differences in Chi-square * $p<$ $0.05 ; * *<0.001$. ${ }^{*}$ Presents missing data in sample. 
Table 3. Associations between parents' MVPA and their children physical activity by gender.

\begin{tabular}{|c|c|c|c|c|c|c|c|c|c|}
\hline & \multicolumn{2}{|c|}{ MVPA Mother } & \multicolumn{2}{|c|}{ MVPA Father } & & \multicolumn{2}{|c|}{ MVPA Mother } & \multicolumn{2}{|c|}{ MVPA Father } \\
\hline & $\beta$ & $95 \% \mathrm{CI}$ & $\beta$ & $95 \% \mathrm{CI}$ & & $\beta$ & $95 \% \mathrm{CI}$ & $\beta$ & $95 \% \mathrm{CI}$ \\
\hline Children & & & & & Adolescents & & & & \\
\hline MVPA total & & & & & MVPA total & & & & \\
\hline All & -0.12 & $(-3.95-0.37)$ & -0.07 & $(-3.60-1.46)$ & All & -0.14 & $(-10.30-2.32)$ & 0.01 & $(-7.20-7.55)$ \\
\hline Girls & -0.03 & $(-1.97-1.43)$ & 0.01 & $(-2.08-2.17)$ & Girls & -0.11 & $(-7.88-3.47)$ & 0.19 & $(-3.18-11.02)$ \\
\hline Boys & 0.03 & $(-1.81-2.48)$ & -0.10 & $(-3.59-1.48)$ & Boys & -0.02 & $(-10.53-9.51)$ & 0.40 & $(-0.12-17.83)$ \\
\hline MVPA in school & & & & & MVPA in school & & & & \\
\hline All & -0.10 & $(-3.09-0.57)$ & -0.02 & $(-2.40-1.92)$ & All & -0.04 & $(-5.74-3.92)$ & -0.06 & $(-6.50-4.03)$ \\
\hline Girls & -0.06 & $(-1.41-0.75)$ & 0.04 & $(-1.23-1.72)$ & Girls & -0.01 & $(-3.81-3.46)$ & 0.84 & $(-2.54-6.17)$ \\
\hline Boys & 0.02 & $(-1.30-1.62)$ & -0.06 & $(-2.31-1.31)$ & Boys & 0.17 & $(-4.17-10.29)$ & 0.39 & $(-0.28-10.92)$ \\
\hline Out-of-school MVPA & & & & & Out-of-school MVPA & & & & \\
\hline All & 0.01 & $(-0.65-0.76)$ & -0.15 & $(-0.61-0.00)$ & All & $-0.23^{* *}$ & $(-5.12-0.27)$ & 0.17 & $(-0.90-4.95)$ \\
\hline Girls & 0.02 & $(-0.90-1.06)$ & -0.08 & $(-1.61-0.82)$ & Girls & -1.17 & $(-4.79-1.11)$ & 0.18 & $(-1.54-5.67)$ \\
\hline Boys & 0.06 & $(-0.72-1.33)$ & -0.09 & $(-1.65-0.64)$ & Boys & -0.27 & $(-8.57-1.81)$ & 0.24 & $(-1.54-8.96)$ \\
\hline MVPA at the weekend & & & & & MVPA at the weekend & & & & \\
\hline All & -0.08 & $(-1.27-0.31)$ & -0.06 & $(-1.36-0.58)$ & All & -0.20 & $(-2.53-0.05)$ & -0.15 & $(-2.42-0.63)$ \\
\hline Girls & -0.10 & $(-1.01-0.33)$ & $0.24^{* *}$ & $(0.00-1.80)$ & Girls & $-0.38^{* *}$ & $(-2.35-0.40)$ & 0.01 & $(-1.32-1.40)$ \\
\hline Boys & 0.04 & $(-0.66-1.00)$ & $-0.27^{* *}$ & $(-2.10-0.19)$ & Boys & 0.01 & $(-1.44-1.51)$ & 0.25 & $(-0.45-2.28)$ \\
\hline
\end{tabular}

MVPA: moderate to vigorous physical activity. $\beta$ : Standardised beta coefficient. ** Significant association in lineal regression $(p<0.001)$. 
Table 4. Associations between parents' mode of commuting to work and their children mode of commuting to school by gender.

\begin{tabular}{|c|c|c|c|c|c|c|c|c|c|}
\hline & \multicolumn{2}{|c|}{ Mother } & \multicolumn{2}{|c|}{ Father } & & \multicolumn{2}{|c|}{ Mother } & \multicolumn{2}{|c|}{ Father } \\
\hline & OR & $95 \% \mathrm{CI}$ & OR & $95 \% \mathrm{CI}$ & & OR & $95 \% \mathrm{CI}$ & OR & $95 \%$ CI \\
\hline Children ACS & & & & & Adolescents ACS & & & & \\
\hline Passive (Ref.) & 1 & & 1 & & Passive (Ref.) & 1 & & 1 & \\
\hline All Active & $4.96^{* *}$ & $(2.68-9.17)$ & $3.64 * *$ & $(1.92-6.91)$ & All Active & 2.11 & $(0.92-4.82)$ & 2.27 & $(0.87-5.92)$ \\
\hline Girls active & $4.48^{* *}$ & $(2.01-9.96)$ & $3.69 *$ & $(1.83-7.47)$ & Girls active & 2.27 & $(0.79-6.53)$ & 2.52 & $(0.60-10.66)$ \\
\hline Boys active & $5.19 *$ & (1.92-14.05) & 3.69 & $(0.65-21.09)$ & Boys active & 1.76 & $(0.45-6.87)$ & 2.02 & $(0.49-8.33)$ \\
\hline Public commuting & & & & & Public commuting & & & & \\
\hline AC + Private (Ref.) & 1 & & 1 & & AC + Private (Ref.) & 1 & & 1 & \\
\hline All public & 1.76 & $(0.47-6.67)$ & $6.28 *$ & $(1.38-28.53)$ & All public & 3.77 * & $(1.79-8.34)$ & $5.28^{* *}$ & $(2.14-13.00)$ \\
\hline Girls public & 1.29 & $(0.26-6.46)$ & $12.62 *$ & $(2.08-76.55)$ & Girls public & $4.59 *$ & $(1.76-11.94)$ & $6.30 *$ & $(2.21-17.94)$ \\
\hline Boys public & 4.34 & $(0.35-53.25)$ & NA & NA & Boys public & 2.28 & $(0.48-10.90)$ & 4.20 & $(0.67-26.52)$ \\
\hline Private commuting & & & & & Private commuting & & & & \\
\hline AC + Public (Ref.) & 1 & & 1 & & $\mathrm{AC}+$ Private (Ref.) & 1 & & 1 & \\
\hline All private & $3.19^{* *}$ & $(2.07-4.93)$ & $4.09^{* *}$ & $(2.66-6.30)$ & All private & $6.03^{* *}$ & (2.99-12.18) & $9.85^{* *}$ & $(4.65-20.88)$ \\
\hline Girls private & $2.24 *$ & $(1.32-3.80)$ & $3.08^{* *}$ & $(1.83-5.16)$ & Girls private & $5.50 * *$ & $(4.46-12.43)$ & 12.72 ** & $(5.01-32.31)$ \\
\hline Boys private & $6.26^{* *}$ & $(2.84-13.81)$ & $7.96^{* *}$ & $(3.48-18.20)$ & Boys private & $17.21 *$ & (2.60-113.70) & $5.08 *$ & (1.35-19.08) \\
\hline
\end{tabular}

OR: odds ratio adjusted for parents' educational level and child age. CI: confidence interval; ACS: active commuting to school. AC: active commuting. NA: not available data for this group. ${ }^{*}$ Statistical association in bivariate regression equation $(p<0.05) .{ }^{* *}$ Statistical association in bivariate regression equation $(p<0.001)$. 


\section{Discussion}

The main findings of the study were: (1) an inverse association was found between fathers-children in the weekend MVPA in children and between mothers-adolescents in out-of-school and weekend MVPA in adolescents, specifically, an inverse association was found in MVPA between mothers-girls; and (2) the different parents' $M C$ to work were positively associated with the MC to school in children and adolescents except for the association AC parents-adolescents and, specifically, the AC was mainly associated between mothers and girls and boys.

\subsection{Physical Activity}

In children, the fathers' MVPA was only positively associated with the girls' weekend MVPA. In addition, an inverse association in MVPA between mothers-boys in children, mother-child out-of-school MVPA and mothers-girls in the weekend PA in adolescents was found.

Accordingly, a modest and positive association between parent-child PA in a systematic review was found (52\% of studies), but no differences were observed in the influence of mothers or fathers on children's PA [16]. However, previously a positive association was found for fathers-boys and mothers-girls PA [41], but the stronger correlation was observed for father-boy PA, and there was a lighter association for mothers-boys and mothers-girls PA [42].

Our results in children showed that fathers' MVPA was positively associated with the weekend MVPA in girls and negatively associated with boys. The positive association between active fathers and active girls can be explained by the role modeling of parents for girls' PA, especially at the weekend. For example, girls whose parents exercised $\geq 3$ times weekly could be almost $50 \%$ more active than girls with sedentary parents. This especially occurred at the weekend where there was a greater interaction between parents and children [43]. In this regard, it has been reported that the fathers were more likely to offer social support to practice PA than mothers, whose main role is taking care of their children during the weekdays because fathers work long hours during the day [44]. Furthermore, the negative association fathers-boys found in the current study can be explained by the low number of parents who met the PA recommendations. This makes it difficult to find clear associations. Additionally, we assume that fathers are not role modeling to children PA but support the practice $[45,46]$.

Our results in adolescents showed that the mother's MVPA was negatively associated with out-of-school MVPA in both (girls and boys) and with girls' MVPA during the weekend. The other parents' associations with boys and girls were not significant. These negative associations can be explained because the adolescents' PA is more independent of the parents' PA. This can be especially accentuated because mothers comply with the MVPA recommendations less than fathers. Additionally, children, as they grow up, can have active behavior independent of their parents and more related to their peers [47]. In this regard, it has been reported in adolescents that paternal and maternal support decreased with age, whereas independent play increased [48]. In addition, a qualitative study showed that girl adolescents received more emotional negative support for PA from parents and less tangible support and direct participation from parents in PA with them [49]. It has been found that it may be that sedentary girls are likely to have sedentary parents, while there may be a weak association between parents and regularly active girls [50].

In general terms, in the current study, no positive association parent-child PA was found. In this regard, a recent systematic review showed a weak correlation between the level of parent and child PA and suggests that we should develop a deeper understanding of associations and mechanisms [51]. Future studies and interventions should investigate the association between parents and their children PA, especially out-of-school and at the weekend, which seems to be the time where there is a greater association. 


\subsection{Mode of Commuting}

In the current study, several positive associations between parents and children in the different MC (active, public, and private) were found. A greater association was found between mothers' AC to work with girls' and boys' ACS than fathers. The fathers' AC to work was only associated with the ACS in girls. This finding could be related to a greater degree of care or responsibility assumed by mothers with their children [52], where mothers were mainly responsible for taking them to school. Another study found that greater mothers' work flexibility was related to a greater number of children's active trips [53]. Furthermore, it was possible to associate the MC of the mothers, but not the fathers, with the ACS of their children [54].

In our study, the association between parents' AC to work and children ACS was stronger in children than adolescents. This could be explained by the higher degree of autonomy and independence of adolescents who no longer depend heavily on parents for commuting [11]. In addition, it has been studied that the parents perceived lower barriers in adolescents than children [55-57]. These factors would cause adolescents to choose a different MC than their parents because they independently commute to school empowered by social interaction among peers [58].

The general results of the current study showed a positive association between public commuting of parents and girls. However, no associations between mothers-boys or fathers-boys were observed. These results could be explained by a possible greater independence of boys compared to girls, which has been previously reported [59]. Girls would prefer to be accompanied by their parents, or parents impose more barriers for independent commuting to girls [60]. Using public transport is important, since, along with walking, they are considered the two best options for independent mobility in children and adolescents [61]. Previous studies have indicated that parents feel more secure and less afraid to allow boys to walk further from home than girls [62,63]. This would affect girls' ACS and increase the use of passive MC.

In the current study, a positive association was observed between the parents' private MC and their children MC. This association was even higher than the observed with AC, especially among parents and adolescents. A greater positive association between mothers and boys' adolescents in private commuting was found. Likewise, a strong association between fathers with adolescents' girls in this mode was observed. In this regard, a Spanish study in schoolchildren of 9-12 years [64] observed an inverse association between the fact that it is more convenient to drive and the accompaniment of their children on foot to school. Parents' convenience of using the car to carry their children has been previously reported as one of the main barriers to ACS [65,66]. In addition, in the case of adolescents, it has been reported that they prefer to be driven to school [67] than another MC. The main problem is that these preferences of young people to use passive MC could be transferred to adult life [64]. The findings from the current study about passive commuting are relevant, since not only are children more likely to use ACS if parents use AC, but also children are still more likely to use passive MC when parents do too.

\subsection{Active Families}

The associations in MVPA and MC could also be bi-directional, that is, they can benefit parents and children [68]. Accordingly, we propose a classification of families according to whether they have reached the MVPA recommendations and according to their use AC (Figure 1). It is important to note that compliance with the MVPA recommendations has been considered as a behavior that is above the AC to be considered active [69]. Therefore, active commuting is a secondary factor. However, the contribution that the $\mathrm{AC}$ has as a means to achieve the recommendations cannot be ignored either. According to the classification, our proposal defines "Active Family" as those parents and children that meet the MVPA recommendations and use AC. "Moderately Active Family" is applied to those who use AC, but parents or children do not meet MVPA recommendations. In this case, the categorization is affected when any member does not meet the MVPA recommendations. The category "Inactive Family" is applied to the families where neither parents nor children meet 
the MVPA recommendations. It makes the entire group inactive, even though some member actively commutes. Finally, "Inactive and Passive Family" includes the families where parents and children do not meet MVPA recommendations and use passive commuting.

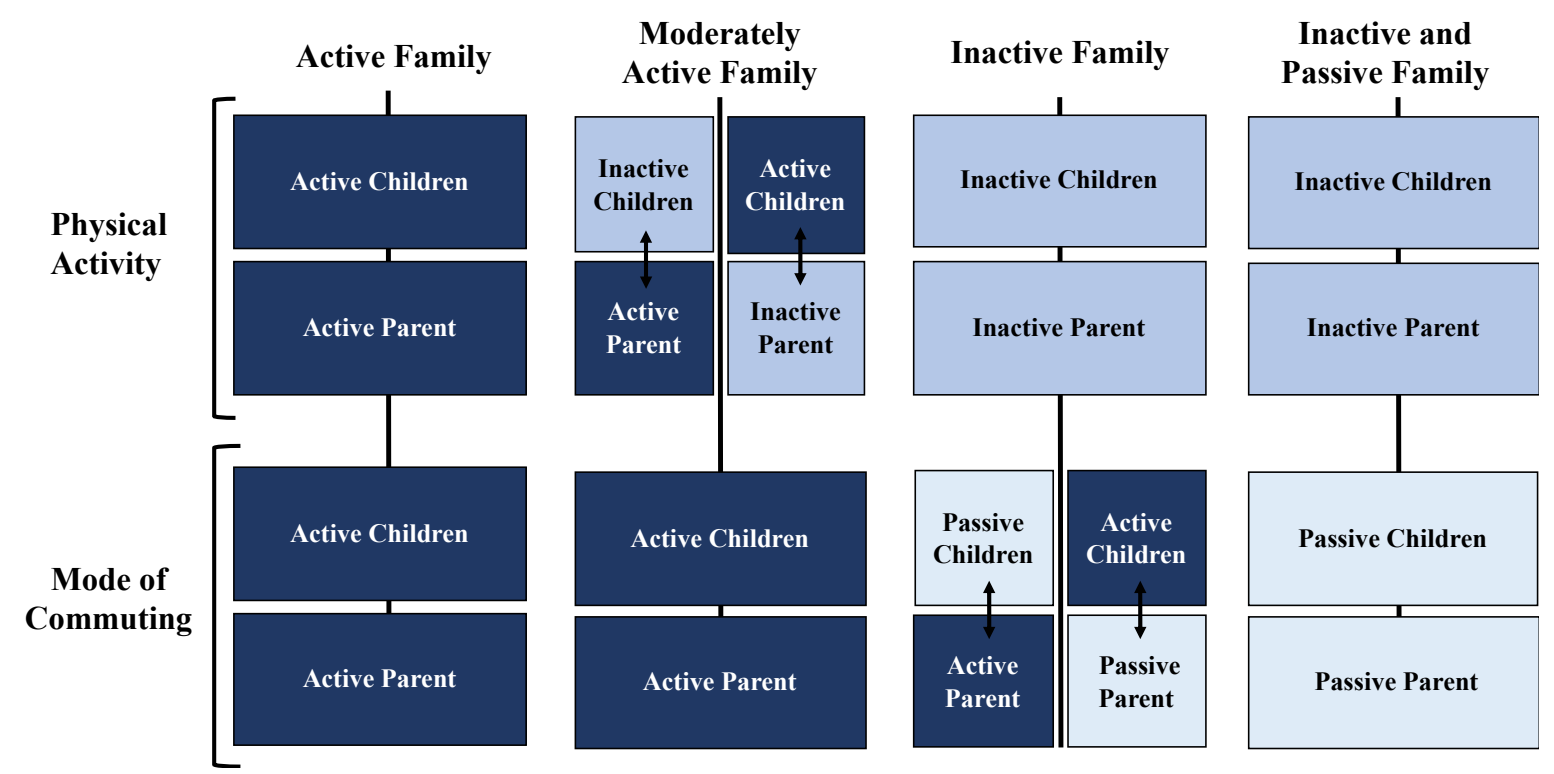

Figure 1. Proposal for classification of families according to compliance with MVPA recommendations and the use of active MC.

For a better interpretation, it should be considered that other members may positively or negatively affect PA or AC (grandparents, siblings, uncles, etc.). Therefore, by pointing to "parent", it may refer to any parental figure influencing children.

\subsection{Limitations}

The main limitation of the study was the cross-sectional design and, therefore, no cause and effect relationship can be established in the associations found. A longitudinal study would be required to determine the direction of the relationship. There was a relevant loss data of sample regarding the initial data collection, because the questionnaires were incomplete. Additionally, a non-randomized sample was included; therefore, it is not possible to generalize results to the population. In addition, a self-reported questionnaire that has a lower objectivity to determine the PA than devices such as accelerometers was used.

Finally, in relation to the mode of commuting, we did not have the distance to and from school (continuous value), and it was not used to establish the impact on AC.

\subsection{Study Application and Projections}

The findings allow targeting interventions and programs at school to promote PA and ACS towards girls and their mothers, which is where there is a greater association. Literature shows that mothers and girls are the ones who do less PA. Thus, promoting ACS in girls would help increase the time dedicated to daily PA. In addition, it is necessary that parents be involved in school activities for the promotion and the practice of PA and to promote healthy behaviors in the educational community. Future studies should include an objective evaluation of PA and ACS that allows one to be precise in the associations found. However, a questionnaire to determine sociodemographic and implicated variables should continue to be applied. Some variables that can be included are the length of the parents' working hours and determining if the siblings play an important role in the association over the parents. 


\section{Conclusions}

The results in the current study demonstrate a weak association between the parent-child MVPA. This lack of association could be related to gender stereotypes, family structure (single parent, extended or reconstituted family, etc.), or social problems, among other factors. More studies should be conducted to further explore the relationships and the associations between parent-child MVPA in different countries and realities. Otherwise, a strong association was found between the MC to work of parents and the MC to school of their children. It was not possible to establish a clear association of the fathers' AC over the mother or vice versa about ACS of their boys and girls. Increasing the parents' AC to work could mean an improvement not only in their own levels of MVPA but also in the MVPA levels and the ACS of their children. Otherwise, attention should be given to the use of passive modes of parents, which are largely associated with the passive modes in children. The results suggest the importance of involving families in the design, the implementation, and the evaluation of interventions in PA and ACS in children and adolescents.

Author Contributions: Conceptualization and design, F.R.-R., F.J.H.-D., P.C.; Acquisition of data: M.J.A.-B., Y.B.-R.; Methodology, F.R.-R., F.J.H.-D., P.C.; Formal analysis, F.R.-R., F.J.H.-D., P.C; Resources, F.R.-R., P.C.; Data curation, F.R.-R.; writing - original draft preparation, F.R.-R., F.J.H.-D., M.J.A.-B., Y.B.-R., P.C.; writing一review and editing, F.R.-R., F.J.H.-D., M.J.A.-B., Y.B.-R., P.C.; supervision, P.C.; project administration, P.C.; funding acquisition, P.C., F.R.-R. All authors have read and agreed to the published version of the manuscript.

Funding: This study was supported by the Spanish Ministry of Economy, Industry and Competitiveness and the European Regional Development Fund (e). Additionally, this study took place thanks to funding from the University of Granada Plan Propio de Investigación 2016-Excellence actions: Unit of Excellence on Exercise and Health (UCEES) — and the Junta de Andalucía, Consejería de Conocimiento, Investigación y Universidades, European Regional Development Fund (ref. SOMM17/6107/UGR). Additionally, it was supported by the Ministry of Education of Chile CONICYT PAI-MEC programme 2015 (MEC 80150030) and the Postdoctoral programme "Becas Chile" 2019 from Agencia Nacional de Investigación y Desarrollo de Chile (ANID).

Acknowledgments: To Chilean and Spanish schoolchildren and their parents who agreed to participate in the study. To researchers Javier Sevil Serrano and Patricio Solís Urra for the valuable collaboration in this work. To Own Research Plan, University of Granada and the Junta de Andalucía, Ministry of Knowledge, Research and Universities. Finally, to Postdoctoral program "Becas Chile" from ANID, Chile.

Conflicts of Interest: The authors declare no conflict of interest.

\section{References}

1. Poitras, V.J.; Gray, C.E.; Borghese, M.M.; Carson, V.; Chaput, J.P.; Janssen, I.; Katzmarzyk, P.; Pate, R.; Gorber, C.G.; Kho, M.; et al. Systematic review of the relationships between objectively measured physical activity and health indicators in school-aged children and youth. Appl. Physiol. Nutr. Metab. 2016, 41, 197-239. [CrossRef]

2. Rhodes, R.E.; Janssen, I.; Bredin, S.S.; Warburton, D.E.; Bauman, A. Physical activity: Health impact, prevalence, correlates and interventions. Psychol. Health 2017, 32, 942-975. [CrossRef]

3. WHO. Global Recommendations on Physical Activity for Health; World Health Organization: Geneva, Switzerland, 2010.

4. Piercy, K.L.; Troiano, R.P.; Ballard, R.M.; Carlson, S.A.; Fulton, J.E.; Galuska, D.A.; George, S.; Olson, R.D. The physical activity guidelines for Americans. JAMA 2018, 320, 2020-2028. [CrossRef]

5. Guthold, R.; Stevens, G.A.; Riley, L.M.; Bull, F.C. Global trends in insufficient physical activity among adolescents: A pooled analysis of 298 population-based surveys with 1.6 million participants. Lancet Child Adolesc. Health 2020, 4, 23-35. [CrossRef]

6. Vancampfort, D.; Van Damme, T.; Firth, J.; Smith, L.; Stubbs, B.; Rosenbaum, S.; Hallgren, M.; Hagemann, N.; Koyanagi, A. Correlates of physical activity among 142,118 adolescents aged 12-15 years from 48 low-and middle-income countries. Prev. Med. 2019, 127, 105819. [CrossRef]

7. Hallal, P.C.; Andersen, L.B.; Bull, F.C.; Guthold, R.; Haskell, W.; Ekelund, U.; Lancet Physical Activity Series Working Group. Global physical activity levels: Surveillance progress, pitfalls, and prospects. Lancet 2012, 380, 247-257. [CrossRef] 
8. Van Hecke, L.; Loyen, A.; Verloigne, M.; Van der Ploeg, H.P.; Lakerveld, J.; Brug, J.; De Bourdeaudhuij, I.; Ekelund, U.; Donnelly, A.; Hendriksen, I.; et al. Variation in population levels of physical activity in European children and adolescents according to cross-European studies: A systematic literature review within DEDIPAC. Int. J. Behav. Nutr. Phys. Act. 2016, 13, 70. [CrossRef]

9. Ha, A.S.; Ng, J.Y.Y.; Lonsdale, C.; Lubans, D.R.; Ng, F.F. Promoting physical activity in children through family-based intervention: Protocol of the "Active 1+FUN" randomized controlled trial. BMC Pub. Health 2019, 19, 218. [CrossRef]

10. Sims, D.; Bopp, M. Using parental active travel behavior and beliefs to predict active travel to school among children. Int. J. Sustain. Transp. 2019, 14, 1-6. [CrossRef]

11. Garcia-Cervantes, L.; Rodriguez-Romo, G.; Esteban-Cornejo, I.; Cabanas-Sanchez, V.; Delgado-Alfonso, A.; Castro-Pinero, J.; Vega, O.; UP \& DOWN Study Group. Perceived environment in relation to objective and self-reported physical activity in Spanish youth. The UP \& DOWN study. J. Sports Sci. 2016, 34, 1423-1429.

12. Arlinghaus, K.R.; Johnston, C.A. Engaging fathers in the promotion of healthy lifestyle behaviors. Am. J. Lifestyle Med. 2017, 11, 216-219. [CrossRef]

13. Christofaro, D.G.D.; Andersen, L.B.; de Andrade, S.M.; de Barros, M.V.G.; Saraiva, B.T.C.; Fernandes, R.A.; Ritti-Dias, R.M. Adolescents' physical activity is associated with previous and current physical activity practice by their parents. J. Pediatr. 2018, 94, 48-55. [CrossRef]

14. Tanaka, C.; Okuda, M.; Tanaka, M.; Inoue, S.; Tanaka, S. Associations of physical activity and sedentary time in primary school children with their parental behaviors and supports. Int. J. Environ. Res. Public. Health. 2018, 15, 1995. [CrossRef]

15. Schoeppe, S.; Röbl, M.; Liersch, S.; Krauth, C.; Walter, U. Mothers and fathers both matter: The positive influence of parental physical activity modeling on children's leisure-time physical activity. Pediatr. Exerc. Sci. 2016, 28, 466-472. [CrossRef]

16. Neshteruk, C.D.; Nezami, B.T.; Nino-Tapias, G.; Davison, K.K.; Ward, D.S. The influence of fathers on children's physical activity: A review of the literature from 2009 to 2015. Prev. Med. 2017, 102, 12-19. [CrossRef]

17. Davison, K.K.; Gicevic, S.; Aftosmes-Tobio, A.; Ganter, C.; Simon, C.L.; Newlan, S.; Manganello, J.A. Fathers' representation in observational studies on parenting and childhood obesity: A systematic review and content analysis. Am. J. Public. Health. 2016, 106, e14-e21. [CrossRef]

18. Lloyd, A.B.; Lubans, D.R.; Plotnikoff, R.C.; Collins, C.E.; Morgan, P.J. Maternal and paternal parenting practices and their influence on children's adiposity, screen-time, diet and physical activity. Appetite 2014, 79, 149-157. [CrossRef]

19. Martin, A.; Kelly, P.; Boyle, J.; Corlett, F.; Reilly, J.J. Contribution of walking to school to individual and population moderate-vigorous intensity physical activity: Systematic review and meta-analysis. Pediatric Exerc. Sci. 2016, 28, 353-363. [CrossRef]

20. Prince, S.A.; Butler, G.P.; Rao, D.P.; Thompson, W. Evidence synthesis Where are children and adults physically active and sedentary?-A rapid review of location-based studies. Health Promot. Chronic Dis. Prev. Can. Res. Policy. Pract. 2019, 39, 67. [CrossRef]

21. Macmillan, A.; Smith, M.; Witten, K.; Woodward, A.; Hosking, J.; Wild, K.; Field, A. Suburb-level changes for active transport to meet the SDGs: Causal theory and a New Zealand case study. Sci. Total Environ. 2020, 714. [CrossRef]

22. Aubert, S.; Barnes, J.D.; Abdeta, C.; Abi Nader, P.; Adeniyi, A.F.; Aguilar-Farias, N.; Tenesaca, D.S.A.; Bhawra, J.; Brazo-Sayavera, J.; Cardon, G.; et al. Global matrix 3.0 physical activity report card grades for children and youth: Results and analysis from 49 countries. J. Phys. Act. Health 2018, 15, S251-S273. [CrossRef] [PubMed]

23. Te Velde, S.J.; Haraldsen, E.; Vik, F.N.; De Bourdeaudhuij, I.; Jan, N.; Kovacs, E.; Bere, E. Associations of commuting to school and work with demographic variables and with weight status in eight European countries: The ENERGY-cross sectional study. Prev. Med. 2017, 99, 305-312. [CrossRef]

24. Rahman, M.L.; Moore, A.; Smith, M.; Lieswyn, J.; Mandic, S. A conceptual framework for modelling safe walking and cycling routes to high schools. Int. J. Environ. Res. Public Health 2020, 17, 3318. [CrossRef] [PubMed] 
25. D’Haese, S.; Van Dyck, D.; De Bourdeaudhuij, I.; Deforche, B.; Cardon, G. The association between objective walkability, neighborhood socio-economic status, and physical activity in Belgian children. Int. J. Behav. Nutr. Phys. Act. 2014, 11, 104. [CrossRef]

26. Rodríguez-López, C.; Villa-González, E.; Pérez-López, I.J.; Delgado-Fernández, M.; Ruiz, J.R.; Chillón, P. Family factors influence active commuting to school in spanish children. Nutr. Hosp. 2013, 28, 756-763. [PubMed]

27. Sigmundová, D.; Badura, P.; Sigmund, E.; Bucksch, J. Weekday-weekend variations in mother-/father-child physical activity and screen time relationship: A cross-sectional study in a random sample of Czech families with 5-to 12-year-old children. Eur. J. Sport. Sci. 2018, 18, 1158-1167. [CrossRef]

28. Craig, C.L.; Cameron, C.; Tudor-Locke, C. Relationship between parent and child pedometer-determined physical activity: A sub-study of the CANPLAY surveillance study. Int. J. Behav. Nutr. Phys. Act 2013, 10, 8. [CrossRef]

29. Stearns, J.A.; Rhodes, R.; Ball, G.D.; Boule, N.; Veugelers, P.J.; Cutumisu, N.; Spence, J.C. A cross-sectional study of the relationship between parents' and children's physical activity. BMC Pub. Health 2016, 16, 1129. [CrossRef]

30. Saint-Maurice, P.F.; Welk, G.J. Validity and calibration of the youth activity profile. PLoS ONE 2015, 10. [CrossRef]

31. Fairclough, S.J.; Christian, D.L.; Saint-Maurice, P.F.; Hibbing, P.R.; Noonan, R.J.; Welk, G.J.; Dixon, P.; Boddy, L.M. Calibration and validation of the youth activity profile as a physical activity and sedentary behaviour surveillance tool for English youth. Int. J. Environ. Res. Pub. Health 2019, 16, 3711. [CrossRef]

32. Tremblay, M.S.; Carson, V.; Chaput, J.P.; Connor Gorber, S.; Dinh, T.; Duggan, M.; Faulkner, G.; Gray, C.E.; Gruber, R.; Janson, K.; et al. Canadian 24-hour movement guidelines for children and youth: An integration of physical activity, sedentary behaviour, and sleep. Appl. Physiol. Nutr. Metab. 2016, 41, S311-S327. [CrossRef] [PubMed]

33. Craig, C.L.; Marshall, A.L.; Sjöström, M.; Bauman, A.E.; Booth, M.L.; Ainsworth, B.E.; Pratt, M.; Ekelund, U.; Yngve, A.; Sallis, J.F.; et al. International physical activity questionnaire: 12-country reliability and validity. Med. Sci. Sports Exerc. 2003, 35, 1381-1395. [CrossRef] [PubMed]

34. Roman-Viñas, B.; Serra-Majem, L.; Hagströmer, M.; Ribas-Barba, L.; Sjöström, M.; Segura-Cardona, R. International physical activity questionnaire: Reliability and validity in a Spanish population. Eur. J. Sport Sci. 2010, 10, 297-304. [CrossRef]

35. PACO Study. Available online: https://profith.ugr.es/paco (accessed on 24 August 2020).

36. Herrador-Colmenero, M.; Pérez-García, M.; Ruiz, J.R.; Chillón, P. Assessing modes and frequency of commuting to school in youngsters: A systematic review. Pediatr. Exerc. Sci. 2014, 26, 291-341. [CrossRef]

37. Segura-Díaz, J.M.; Rojas-Jiménez, Á.; Barranco-Ruiz, Y.; Murillo-Pardo, B.; Saucedo-Araujo, R.G.; Aranda-Balboa, M.J.; Herrador-Colmenero, M.; Villa-González, E.; Chillón, P. Feasibility and Reliability of a Questionnaire to Assess the Mode, Frequency, Distance and Time of Commuting to and from School: The PACO Study. Int. J. Environ. Res. Public Health 2020, 17(14), 5039. [CrossRef]

38. Chillón, P.; Herrador-Colmenero, M.; Migueles, J.H.; Cabanas-Sánchez, V.; Fernández-Santos, J.R.; Veiga, Ó.L.; Castro-Piñero, J.; UP \& Down Study Group. Convergent validation of a questionnaire to assess the mode and frequency of commuting to and from school. Scand. J. Pub. Health 2017, 45, 612-620.

39. Escobar-Gómez, D.; Rodríguez-Rodríguez, F.; Villa-González, E.; Esteban-Cornejo, I. Chillón PFiabilidad y viabilidad de un cuestionario autorreportado sobre el modo tiempo y distancia de desplazamiento en niños y adolescents. Retos 2020, 37, 379-385.

40. Herrador-Colmenero, M.; Ruiz, J.R.; Ortega, F.B.; Segura-Jiménez, V.; Álvarez-Gallardo, I.C.; Camiletti-Moirón, D.; Estévez-López, F.; Delgado-Fernández, M.; Chillón, P. Reliability of the ALPHA environmental questionnaire and its association with physical activity in female fibromyalgia patients: The al-Ándalus project. J. Sports Sci. 2015, 33, 850-862. [CrossRef]

41. Gustafson, S.L.; Rhodes, R.E. Parental correlates of physical activity in children and early adolescents. Sports Med. 2016, 36, 79-97. [CrossRef]

42. Yao, C.A.; Rhodes, R.E. Parental correlates in child and adolescent physical activity: A meta-analysis. Int. J. Behav. Nutr. Phys. Act. 2015, 12, 10. [CrossRef]

43. Madsen, K.A.; McCulloch, C.E.; Crawford, P.B. Parent modeling: Perceptions of parents' physical activity predict girls' activity throughout adolescence. J. Pediatr. 2009, 154, 278-283. [CrossRef] [PubMed] 
44. Solomon-Moore, E.; Toumpakari, Z.; Sebire, S.J.; Thompson, J.L.; Lawlor, D.A.; Jago, R. Roles of mothers and fathers in supporting child physical activity: A cross-sectional mixed-methods study. BMJ Open 2018, 8, e019732. [CrossRef] [PubMed]

45. Wright, K.E.; Furzer, B.J.; Licari, M.K.; Dimmock, J.A.; Jackson, B. The effect of parental logistic support on physical activity in children with, or at risk of, movement difficulties. J. Sci. Med. Sport 2019, 23, S1440-S2440. [CrossRef] [PubMed]

46. Jelleyman, C.; McPhee, J.; Brussoni, M.; Bundy, A.; Duncan, S. A cross-sectional description of parental perceptions and practices related to risky play and independent mobility in children: The New Zealand state of play survey. Int. J. Environ. Res. Public Health 2019, 16, 262. [CrossRef]

47. Lawler, M.; Heary, C.; Nixon, E. Peer Support and Role Modelling Predict Physical Activity Change among Adolescents over Twelve Months. J. Youth Adolesc. 2020, 49, 1503-1516. [CrossRef]

48. Kirby, J.; Levin, K.A.; Inchley, J. Parental and peer influences on physical activity among Scottish adolescents: A longitudinal study. J. Phys. Act. Health 2011, 8, 785-793. [CrossRef]

49. Wright, M.S.; Wilson, D.K.; Griffin, S.; Evans, A. A qualitative study of parental modeling and social support for physical activity in underserved adolescents. Health Educ. Res. 2010, 25, 224-232. [CrossRef]

50. Bauer, K.W.; Neumark-Sztainer, D.; Fulkerson, J.A.; Hannan, P.J.; Story, M. Familial correlates of adolescent girls' physical activity, television use, dietary intake, weight, and body composition. Int. J. Behav. Nutr. Phys. Act. 2011, 8, 25. [CrossRef]

51. Petersen, T.L.; Møller, L.B.; Brønd, J.C.; Jepsen, R.; Grøntved, A. Association between parent and child physical activity: A systematic review. Int. J. Behav. Nutr. Phys. Act. 2020, 17,1-16. [CrossRef]

52. Zahra, J.; Sebire, S.J.; Jago, R. "He's probably more Mr. sport than me"-a qualitative exploration of mothers' perceptions of fathers' role in their children's physical activity. BMC Pediatr. 2015, 15, 101. [CrossRef]

53. Sener, I.N.; Lee, R.J.; Sidharthan, R. An examination of children's school travel: A focus on active travel and parental effects. Transp. Res. Pt. A Policy Pract. 2019, 123, 24-34. [CrossRef]

54. Kobel, S.; Wartha, O.; Steinacker, J.M. Correlates of active transport to school in german primary school children. Dtsch. Z. Sportmed. 2019, 70, 67-74. [CrossRef]

55. Huertas-Delgado, F.J.; Chillón, P.; Barranco-Ruiz, Y.; Herrador-Colmenero, M.; Rodríguez-Rodríguez, F.; Villa-González, E. Parental perceived barriers to active commuting to school in Ecuadorian youth. J. Transp. Health 2018, 10, 290-296. [CrossRef]

56. Aranda-Balboa, M.J.; Huertas-Delgado, F.J.; Herrador-Colmenero, M.; Cardon, G.; Chillón, P. Parental barriers to active transport to school: A systematic review. Int. J. Public Health 2019, 65, 1-12. [CrossRef] [PubMed]

57. Palma, X.; Chillón, P.; Rodríguez-Rodríguez, F.; Barranco-Ruiz, Y.; Huertas-Delgado, F.J. Perceived parental barriers towards active commuting to school in Chilean children and adolescents of Valparaíso. Int. J. Sustain. Transp. 2019, 14, 1-8. [CrossRef]

58. Lopes, F.; Cordovil, R.; Neto, C. Independent mobility and social affordances of places for urban neighborhoods: A youth-friendly perspective. Front. Psychol. 2018, 9, 2198. [CrossRef]

59. Barnett, A.; Sit, C.H.; Mellecker, R.R.; Cerin, E. Associations of socio-demographic, perceived environmental, social and psychological factors with active travel in Hong Kong adolescents: The iHealt $(\mathrm{H})$ cross-sectional study. J. Transp. Health 2019, 12, 336-348. [CrossRef]

60. Larsen, K.; Gilliland, J.; Hess, P.; Tucker, P.; Irwin, J.; He, M. The influence of the physical environment and sociodemographic characteristics on children's mode of travel to and from school. Am. J. Public Health 2009, 99, 520-526. [CrossRef]

61. Sarjala, S.; Broberg, A.; Hynynen, A. Children and youth transport in different urban morphological types. J. Transp. Land 2016, 9, 87-103. [CrossRef]

62. Carver, A.; Timperio, A.; Hesketh, K.; Crawford, D. Are children and adolescents less active if parents restrict their physical activity and active transport due to perceived risk? Soc. Sci. Med. 2010, 70, 1799-1805. [CrossRef]

63. Esteban-Cornejo, I.; Carlson, J.A.; Conway, T.L.; Cain, K.L.; Saelens, B.E.; Frank, L.D.; Glanz, K.; Roman, C.G.; Sallis, J.F. Parental and adolescent perceptions of neighborhood safety related to adolescents' physical activity in their neighborhood. Res. Q. Exerc. Sport 2016, 87, 191-199. [CrossRef] [PubMed]

64. Solana, A.A.; Mandic, S.; Lanaspa, E.G.; Gallardo, L.O.; Casterad, J.Z. Parental barriers to active commuting to school in children: Does parental gender matter? J. Transp. Health 2018, 9, 141-149. [CrossRef] 
65. Faulkner, G.E.J.; Richichi, V.; Buliung, R.N.; Fusco, C.; Moola, F. What's “quickest and easiest?": Parental decision making about school trip mode. Int. J. Behav. Nutr. Phys. Act. 2010, 7, 62-73. [CrossRef] [PubMed]

66. Trapp, G.S.A.; Giles-Corti, B.; Christian, H.E.; Bulsara, M.; Timperio, A.F.; McCormack, G.R.; Villaneuva, K.P. On your bike! a cross-sectional study of the individual, social and environmental correlates of cycling to school. Int. J. Behav. Nutr. Phys. Act. 2011, 8, 123-132. [CrossRef]

67. Mandic, S.; Hopkins, D.; García Bengoechea, E.; Flaherty, C.; Williams, J.; Sloane, L.; Moore, A.; Spence, J.C. Adolescents' perceptions of cycling versus walking to school: Understanding the New Zealand context. J. Transp. Health 2017, 4, 294-304. [CrossRef]

68. Niermann, C.Y.; Gerards, S.M.; Kremers, S.P. Conceptualizing family influences on children's energy balance-related behaviors: Levels of Interacting Family Environmental Subsystems (The LIFES Framework). Int. J. Environ. Res. Public Health 2018, 15, 2714. [CrossRef]

69. Mora-Gonzalez, J.; Rodríguez-López, C.; Cadenas-Sanchez, C.; Herrador-Colmenero, M.; Esteban-Cornejo, I.; Huertas-Delgado, F.J.; Ardoy, D.; Ortega, F.; Chillón, P. Active commuting to school was inversely associated with academic achievement in primary but not secondary school students. Acta Paediatr. 2017, 106, 334-340. [CrossRef]

(C) 2020 by the authors. Licensee MDPI, Basel, Switzerland. This article is an open access article distributed under the terms and conditions of the Creative Commons Attribution (CC BY) license (http://creativecommons.org/licenses/by/4.0/). 